\title{
Development of Learning and Memory in Aplysia. I. Functional Assembly of Gill and Siphon Withdrawal
}

\author{
Catharine H. Rankin, Mark Stopfer, Emilie A. Marcus, and Thomas J. Carew \\ Departments of Psychology and Biology, Yale University, New Haven, Connecticut 06520
}

The marine mollusc Aplysia californica provides an excellent preparation with which to examine the development of the neuronal control of behavior for 2 reasons: first, adult Aplysia exhibit a variety of behaviors that are well understood in cellular terms; and second, the development of Aplysia from embryo to adult has been studied in considerable detail. Among the best understood behaviors in Aplysia are the withdrawal responses of the mantle organs (the gill, siphon, and mantle shelt), which exhibit 2 different kinds of behaviors: (1) "spontaneous" contractions that are part of a fixed action pattern, a respiratory pumping sequence of the mantle organs, and (2) reflex contractions in response to tactile stimuli. We have examined the development of both of these withdrawal behaviors in juvenile stages 9-12 and found that they are functionally assembled according to different ontogenetic timetables.

Spontaneous contractions. As soon as the siphon and gill emerge, in stages 9 and 10, respectively, they each show a high rate of spontaneous contraction that gradually diminishes throughout subsequent stages until it reaches the low rate typical of adults (stage 13). Since the siphon emerges first, it already exhibits a significant decline in its spontaneous activity (e.g., in stage 11) when the gill's spontaneous activity is at its highest. In addition to a developmental trend in the rate of contractions, there was also a clear developmental progression in the degree of cocontraction of the siphon and gill during spontaneous contractions. In adults, the siphon and gill show a very high degree of cocontraction during spontaneous pumping. However, in juvenile animals, there was a very low degree. Thus, it appears that the siphon and gill withdrawal components of the fixed action pattern become progressively more functionally coupled during juvenile development.

Reflex contractions. As soon as the siphon and gill emerge in their respective developmental stages, they exhibit a brisk withdrawal reflex to tactile stimulation of the siphon. Moreover, at each developmental stage, reflex siphon contractions were graded as a function of stimulus intensity, as

\footnotetext{
Received Apr. 1, 1986; revised June 30, 1986; accepted July 1, 1986.

We wish to thank David Cash, Beverly Cassidy, and Deda Gillespie for their excellent help in data analysis; Thomas Nolen for helpful comments on an early version of the manuscript; and Eisha Lee for her artwork in Figure 1. We also thank the Howard Hughes Medical Institute and Tom Capo for generously supplying juvenile Aplysia. This work was supported by NIH CDA Award 7-K02MH00081-09, NIH BRSG Grant 507-RR-0750 15, and NSF Grant BNS 8311300 (T.J.C.).

Correspondence should be addressed to Thomas J. Carew, Department of Psychology, Yale University, P.O. Box 11 A, Yale Station, New Haven, CT 06520. Copyright (C) 1987 Society for Neuroscience $0270-6474 / 87 / 010120-13 \$ 02.00 / 0$
}

they are in the adult. Finally, throughout development tactile stimulation of the siphon invariably evoked coincident contractions of both the siphon and the gill, which is characteristic of the adult reflex. Thus, unlike the fixed action pattern that takes several weeks to mature, the defensive withdrawal reflex closely resembles the adult form as soon as the effector organs emerge during juvenile development.

Our results show that a reflex and a fixed action pattern, which utilize a common set of effector organs, emerge according to different developmental timetables. It is now possible to begin to test specific hypotheses concerning the developmental assembly of these behaviors on a cellular level.

It has long been appreciated that important insights into the neural organization of behavior can be obtained by examining behavior from a developmental perspective (Hamberger, 1963, 1968; Weisel and Hubel, 1965; Immelmann, 1969; Konishi and Nottebohm, 1969; Marler and Mundinger, 1971). Invertebrate animals have been particularly useful for such an approach, because it has often been possible in these preparations to extend a developmental analysis to a cellular or mechanistic level. Thus, in a number of invertebrate systems, it has been possible to specify critical changes in underlying neuronal circuitry during development that permit the expression of a variety of behaviors, ranging from simple reflexes to complex, centrally programmed fixed action patterns (Bentley and Hoy, 1970; Davis and Davis, 1973; Lang et al., 1977; Truman, 1980; Levine and Truman, 1983; Fricke, 1984).

The marine mollusc Aplysia californica offers several advantages for this kind of developmental approach to the analysis of behavior. First, the development of Aplysia from embryo to adult has been analyzed in considerable detail (Kriegstein et al., 1974; Kriegstein, 1977a, b; Schacher et al., 1979a, b; McAllister et al., 1983; Jacob, 1984). Second, Aplysia exhibits a wide variety of discrete and quantifiable behaviors that can be traced across clearly defined developmental stages (Kriegstein, 1977a), and the neural circuitry underlying many of these behaviors has been extensively analyzed in the adult. These behaviors include defensive responses such as gill and siphon withdrawal (Kupfermann and Kandel, 1969; Kupfermann et al., 1974), inking (Carew and Kandel, 1977; Byrne, 1980), tail withdrawal (Walters et al., 1983; Cleary and Byrne, 1985), and escape locomotion (Jahan-Parwar and Fredman, 1978a, b; Hening et al., 1979), as well as appetitive responses such as feeding (Kupfermann, 1974a, b), and egg-laying (Kupfermann, 1967; Kupfermann and Kandel, 1970; Mayeri et al., 1979a, b). Finally, a number of these behavioral responses have been shown to be modifiable by 
learning, and in some cases, it has been possible to study the mechanisms underlying the learning in cellular, biophysical, and molecular detail (Klein and Kandel, 1978, 1980; Castellucci et al., 1980; Carew et al., 1983; Hawkins et al., 1983; Kandel et al., 1983; Walters and Byrne, 1983; Ocorr et al., 1985; for reviews see Carew, 1986; Hawkins et al., 1986).

On a cellular level, the withdrawal responses of the mantle organs (the gill, siphon, and mantle shelf) are among the best understood behaviors in Aplysia. These mantle organs exhibit 2 classes of behaviors: (1) an exogenously triggered reflex contraction in response to tactile stimuli; and (2) an endogenously triggered ("spontaneous") contraction, which is part of a fixed action pattern, a respiratory pumping sequence of the mantle organs (Kupfermann and Kandel, 1969; Peretz, 1969; see Kandel, 1976). The neural circuitry underlying the withdrawal reflex consists of an identified cluster of primary mechanoafferent sensory neurons that connect directly to a number of identified interneurons, as well as to identified gill and siphon motor neurons (Castellucci et al., 1970; Byrne et al., 1978; for review see Kandel, 1976). The fixed action pattern circuit consists of 2 identified clusters of interneurons that are the central command elements responsible for driving identified premotor and motor neurons involved in the pattern generation underlying respiratory pumping (Byrne and Koester, 1978; Byrne, 1983; Koester, 1983).

In the present paper we describe the development of reflex and spontaneous contractions of the gill and siphon. We find that reflex (exogenous) control of the mantle organs developmentally precedes spontaneous (endogenous) control, demonstrating that the functional assembly of a reflex and a fixed action pattern, which utilize a common set of effector organs, can occur independently according to different developmental timetables. In the second paper of this series (Rankin and Carew, 1987), we describe another developmental sequence occurring in parallel with the functional assembly of the reflex. This sequence involves the differential emergence of different forms of learning and memory in the siphon withdrawal component of this reflex system. In the final paper of this series (Nolen et al., 1987), we describe experiments focusing on the emergence of learning in the gill withdrawal component of the reflex, as well as on the central neural correlates of learning in the developing CNS.

Some of the results presented in this paper have been previously presented in preliminary form (Carew et al., 1985, 1986).

\section{Materials and Methods}

\section{Adult animals}

Ten adult $A$. californica weighing 100-200 gm were used. The animals were obtained from Pacific Bio-Marine Laboratories, Venice, CA, and were housed separately in perforated pans within a 300 gal tank of constantly circulating aerated artificial seawater (Instant Ocean) at room temperature $\left(20-22^{\circ} \mathrm{C}\right)$.

Behavioral procedures. The procedure used to restrain animals and record gill and siphon withdrawal was similar to that used by Pinsker et al. (1970) and Carew et al. (1979). The animals were restrained in a small, wax-bottomed Lucite aquarium $(12 \times 11 \times 23 \mathrm{~cm})$ by pinning their tails to the bottom and looping and clamping soft tubing tightly about their necks. To reveal the gill, the parapodia and mantle were retracted with stainless stecl hooks fashioned from syringe necdles. A small, black Lucite platform was inserted beneath the gill in order to keep it on a level surface and to provide visual contrast for videotaping (see below). Animals were rested for an hour after being restrained before an experiment was begun. Throughout the experiment freshly aerated, room-temperature artificial seawater (ASW) was circulated through the aquarium.

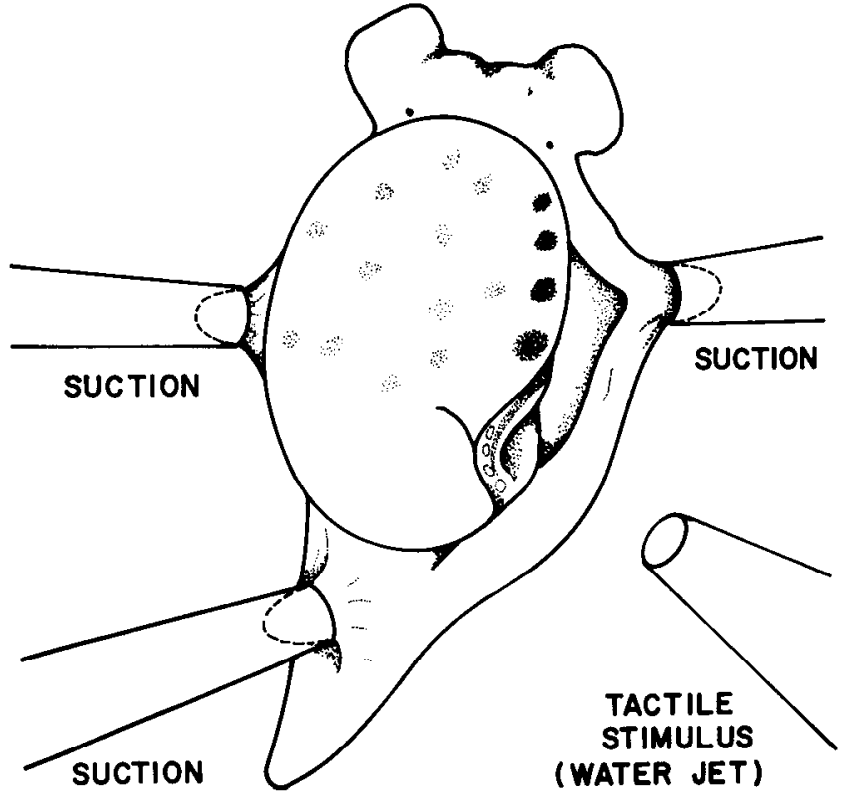

Figure 1. Experimental preparation for studying spontaneous and reflexive withdrawal. A stage 10 juvenile Aplysia is shown restrained with 3 suction micropipettes. Reflex siphon withdrawal was evoked by a brief tactile stimulus (water jet). To provide a sense of scale, this animal was approximately $1 \mathrm{~mm}$ in axial length.

Two different experimental procedures were used: (1) Spontaneous contractions were measured in animals that were first unrestrained and then restrained, and observed in the absence of any delivered stimuli. (2) Evoked contractions were measured using 10 tactile stimuli at a 30 sec interstimulus interval (ISI). Evoked responses that coincided with spontaneous contractions (determined by slow-motion playback) were not scored (see Rankin and Carew, 1987). Reflex withdrawals were triggered by stimulating the siphon with a hand-held soft nylon bristle clamped in a hemostat (Carew et al., 1981). The bristle flexed to its full extent with direct application to the skin so as to deliver a stimulus of relatively constant intensity from one application to the next.

\section{Juvenile animals}

Sixty-three juvenile $A$. californica ranging $0.8-8.0 \mathrm{~mm}$ in length were used. The animals were laboratory-cultured specimens obtained from the Howard Hughes Medical Institute, Woods Hole, MA. The animals were maintained at $15^{\circ} \mathrm{C}$ in groups of 4-8 on seaweed (Gracillaria) in $50 \mathrm{ml}$ plastic centrifuge tubes filled with seawater obtained from Marine Biological Laboratories, Woods Hole, MA. The animals studied were postmetamorphic juveniles.

Kriegstein (1977b) described a set of external morphological criteria that divided developing Aplysia into 13 clearly defined stages: stages 15 are larval stages; stages $6-7$, metamorphic stages; stages $8-12$, juvenile stages; and stage 13, adult. In the experiments reported here, we used animals in stages 9-13. Within a given stage the animals continue to change in appearance, so we developed additional within-stage morphological criteria that allowed us to work with animals as close in age as possible within a stage. Using Kriegstein's (1977b) criteria in combination with our own, animals were staged as follows. Stage 9 animals were at least $36 \mathrm{~d}$ posthatching. They were pink, had no operculum, and measured $0.8-1.0 \mathrm{~mm}$ in length. Stage 10 animals were at least 40 d posthatching. They had white spots over the eyes and 4-10 white spots on the rim of the siphon, and were $1.0-1.5 \mathrm{~mm}$ in length (for example, see Fig. 1). Stage 11 animals were at least $47 \mathrm{~d}$ posthatching and were $1.5-3.0 \mathrm{~mm}$ in length. The rhinophores werc seen only as rudimentary buds above the eyes. Stage 12 animals were at least $60 \mathrm{~d}$ posthatching. They were $6.0-8.0 \mathrm{~mm}$ in length, had well-developed anterior tentacles and rhinophores, and had white spots distributed over their bodies, with large patches of white on the parapodia. The genital groove was visible on the right side of the animal stretching from the anterior insertion of the parapodia to the propodium. 
Behavioral procedures. A Zeiss stereomicroscope (model SV8) fitted with a trinocular attachment permitled videoldping with a color video camera (JVC S-62U). The microscope stage (Diagnostics) provided both bright- and dark-field illumination. A timing signal from a video timer (Panasonic Time-Date Generator WJ-810) was superimposed onto the video image. Image and signal were recorded by a videotape recorder (Panasonic NV-8950), which also permitted slow-motion and stop-frame playback analysis when displayed upon a high-resolution color video monitor (Sony PMV-1270Q).

Each animal was restrained with 3 suction micropipettes mounted on micromanipulators and was positioned so that the siphon and gill were clearly visible. Electrodes were pulled from polyethylene 10 plastic tubing with tip diameters from 45 to $100 \mu \mathrm{m}$. These were used to hold the animal underwater, but above the substrate, from both sides (on the parapodia) and the tail (see Fig. 1). To elicit a withdrawal reflex, a fourth manipulator was used to position a seawater-filled glass micropipette (tip size $\sim 100 \mu \mathrm{m}$ ) that was attached to a Picospritzer II (General Valve Corporation) set to deliver a $50 \mathrm{msec}$ controlled pressure water jet stimulus to the siphon.

Because of the small size of stage 9 animals, an accessory lens $(2 \times$, providing a total magnification of $128 \times$ ) was used to visualize the siphon. The smallest-tipped suction micropipettes (tips $45-50 \mu \mathrm{m}$ ) were used to restrain stage 9 animals. For stage 10 and 11 animals a Zeiss DS $f 100$ lens and suction micropipettes with tips $80-100 \mu \mathrm{m}$ were used. Stage 12 animals were too large to be restrained by the suction micropipettes. These animals were restrained in a seawater-filled petri dish with a Sylgard floor by retracting their parapodia with minutin pins $(100 \mu \mathrm{m})$ to provide a view of the siphon and the gill. Once the animals were pinned, the micropipette from the Picospritzer was directed toward the siphon.

Surgical procedures. The relative contribution of the CNS to siphon withdrawal in stage 11 animals was studied by examining the effects of the removal of the abdominal ganglion on both spontaneous and evoked contractions. The animals were anesthetized by placing them in isotonic $\mathrm{MgCl}_{2}$ for $15 \mathrm{~min}$. They were then transferred to Sylgard-coated petri dishes containing ASW (Instant Ocean). To secure the animals during surgery, micropins were inserted through the oral cavity and the posterior tip of the foot, pinning the animal ventral side up. An incision was made along the midline of the foot extending from the propodium to the tail; 2 micropins were inserted on either side of the incision to expose the internal organs. The esophagus was removed by making a cut at each end, one posterior to the buccal mass and the second near the gut. In this configuration it was possible to see the entire CNS.

The abdominal ganglion was identified on the basis of its position, shape, and connections to the periphery. It lies at the anterior edge of the gut and has a characteristic asymmetrical shape: the left hemiganglion is elongated and attached to the pleural ganglion by a long connective, while the right hemiganglion is spherical and is joined to the pleurals by a shorter connective. In addition to the connectives, there are 3 peripheral nerves that run from the ganglion to the mantle organs. The siphon and genital-pericardial nerves exit the left hemiganglion, and the siphon nerve runs posteriorly to the site where it enters the siphon; the branchial nerve exits from the right hemiganglion and enters the gill directly underneath the abdominal ganglion (for a diagram, see Fig. 6 in Nolen et al., 1987).

In experimental (deganglionated) animals, the siphon, branchial, and genital-pericardial nerves, as well as both connectives, were cut using glass micropipettes broken at the tip, and the abdominal ganglion was removed. In the sham-operated control group, the surgical procedure was identical, except that the nerves and connectives were left intact and the ganglion was not removed. Following surgery, the micropins were removed and the animals were allowed to recover for $1 \mathrm{hr}$ in normal ASW before behavioral observations were made. No attempt was made to seal the incision after surgery. Both experimental and shamoperated control animals showed normal head and body movements 1 hr after surgery; the general behavior of both groups appeared qualitatively similar. A double-blind procedure was used in assessing the siphon reflex amplitude in deganglionated and sham-operated animals: first, the experimenter restraining the animals and delivering the stimuli did not know the experimental condition of the animals; second, another independent observer (also blind to the experimental conditions) traced the responses from the video monitor for subsequent quantitative analysis (see below).

\section{Response measures}

In juvenile animals, siphon reflex amplitude was quantified by tracing the outline of the siphon both immediately before stimulation and at the peak of contraction (both of which could be reliably determined by repeated slow-motion playback and stop-frame analysis). The siphon area tracings were then digitized and quantified by a computerized Bioquant II system (R\&M Biometrics, Nashville, TN), and the response amplitude was assessed by computing the percentage reduction in siphon area. Response amplitude, rather than response duration, was used as an index of reflex magnitude for the siphon. These 2 measures (amplitude and duration) are highly correlated in adult Aplysia (Stopfer and Carew, 1986). However, in juvenile animals response duration appears to be a more variable measure than amplitude. Thus, all measures of reflex magnitude in juveniles are expressed in terms of amplitude.

Spontaneous contractions. Spontaneous contractions of the siphon were studied in both freely moving and restrained animals. As the gill is not externally visible, spontaneous gill contractions could be only studied in restrained animals. For observations of unrestrained animals, Aplysia of each stage (9-12) were individually given a 15 min rest and were then videotaped for $15 \mathrm{~min}$. For the observation of spontaneous contractions in restrained animals, animals of these same juvenile stages (9-12) were restrained in such a way that the siphon and gill were clearly visible, were rested for $15 \mathrm{~min}$, and then were videotaped for $15 \mathrm{~min}$.

Evoked contractions. Reflex contractions were measured with tactile stimuli of increasing and then decreasing intensity to obtain a stimulusresponse curve relating stimulus intensity to contraction amplitude. Each animals (stages 9-11) was first restrained; then the micropipette from the Picospritzer was aimed at the siphon by bringing it up to touch the siphon. The pipette was then gradually moved away parallel to the long axis of the pipette, until the tip was $1.5 \mathrm{~cm}$ from the siphon, just below the water surface. Stimuli of various intensities were generated by triggering a constant-intensity microjet of seawater at the siphon at progressively closer distances (in $1 \mathrm{~mm}$ increments) until the micropipette touched the siphon. Two stimuli were delivered at each distance, with a $30 \mathrm{sec}$ interval between successive stimuli; juvenile animals do not habituate to stimuli at this ISI (Rankin and Carew, 1987). The average response to these 2 stimuli constituted a single score for each distance. The animals were then rested for $15 \mathrm{~min}$ before a second series of stimuli was presented, beginning with the micropipette next to the siphon and moving it away in $1 \mathrm{~mm}$ increments until it was $1.5 \mathrm{~cm}$ away. Again, 2 stimuli were presented at each distance separated by a $30 \mathrm{sec}$ ISI.

The intensities of stimuli used to trigger siphon withdrawal ranged from $1 \mathrm{mg}$ (the weakest) to approximately $8 \mathrm{mg}$ (the strongest). These intensities were determined by aiming the micropipette at the tip of a suction electrode $(\sim 100 \mu \mathrm{m}$ diameter) pulled from polyethylene 10 tubing (see above) and measuring with stop-frame video playback the excursion of the suction electrode tip in response to water jet stimuli delivered at different distances. The force generated to produce these movements was then estimated using fine hairs of varying lengths, which, when maximally bent in contact with the suction electrode, produced excursions comparable to those of the water jet stimuli. These hairs were then calibrated for their maximum force (to the nearest $0.1 \mathrm{mg}$ ) on an electronic balance.

Concurrence of gill and siphon contractions. During spontaneous contractions in stage 11 and adult animals, spontaneous contractions were quantified by analyzing videotapes of restrained animals twice: first, the relative amplitudes and times of the peak contraction of the gill were measured; second, relative amplitudes and times of the peak contraction of the siphon were measured. ("Relative amplitude" was scored on a $1-3$ scale, where 1 is a $<10 \%$ reduction of organ area; $2,10-40 \%$; and $3,>40 \%$ ). Later, the 2 lists were combined: gill and siphon movements occurring within a period of $1 \mathrm{sec}$ of each other were defined as concurrent. A percentage concurrence score was then obtained for siphon and gill contractions having relative amplitudes of 2 or 3 , using the following equation: $(2 C / S+G) \times 100$, where $C$ is the number of concurrent contractions, $S$ is the number of siphon contractions, and $G$ is the number of gill contractions. Thus, complete lack of concurrence would yield a score of $0.0 \%$ and complete concurrence, a score of $100 \%$. To further analyze concurrence of siphon and gill contractions, the distribution of intervals between spontancously occurring siphon and gill contractions was analyzed. Specifically, the interval between each 
STAGE 9

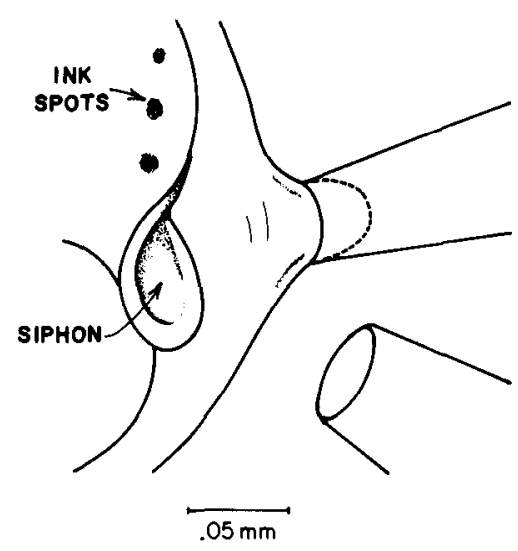

STAGE II

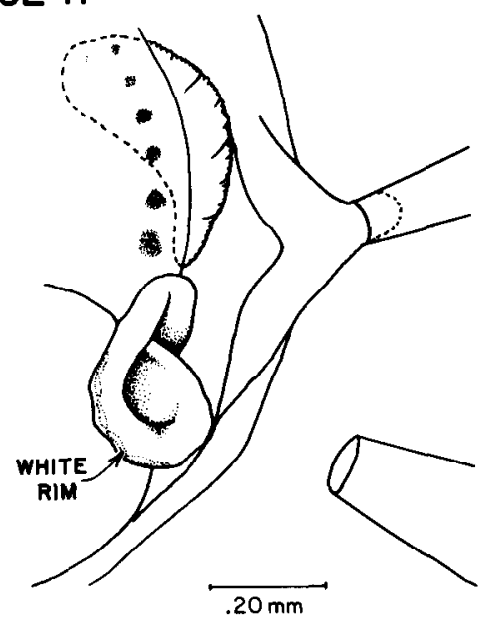

STAGE 10

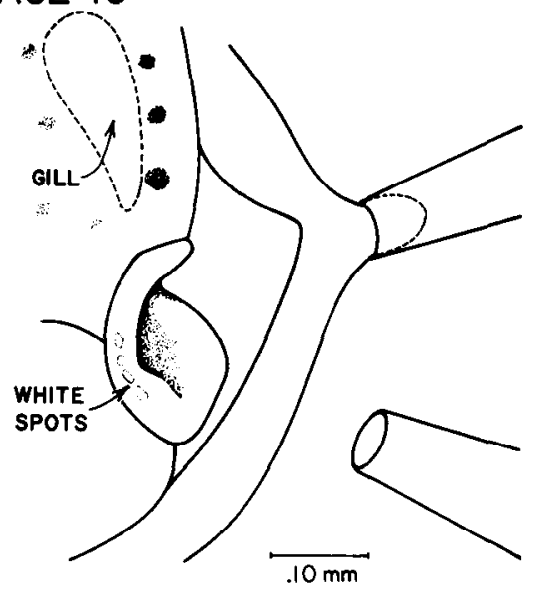

STAGE 12

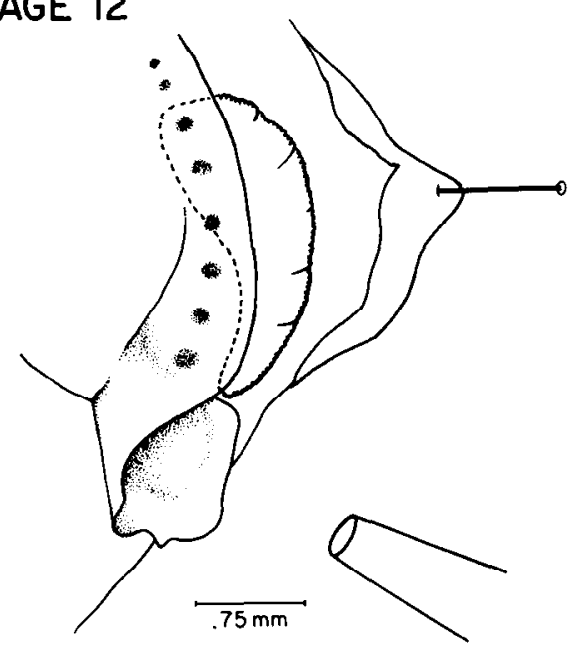

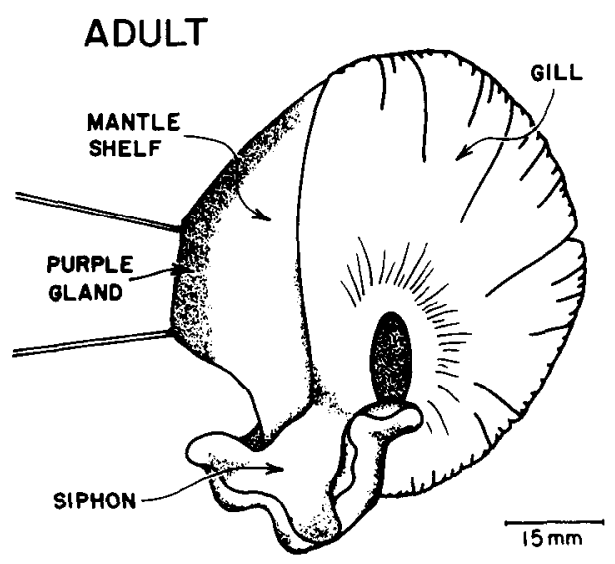

Figure 2. Development of the mantle organs. The progressive development of the siphon and gill is shown from stage 9 to adult. The siphon first appears in stage 9 . The gill first appears in stage 10 but is not directly visible for study until about a week later, in stage 11 . Note the change in scale for each stage. (See text for details.) 
A

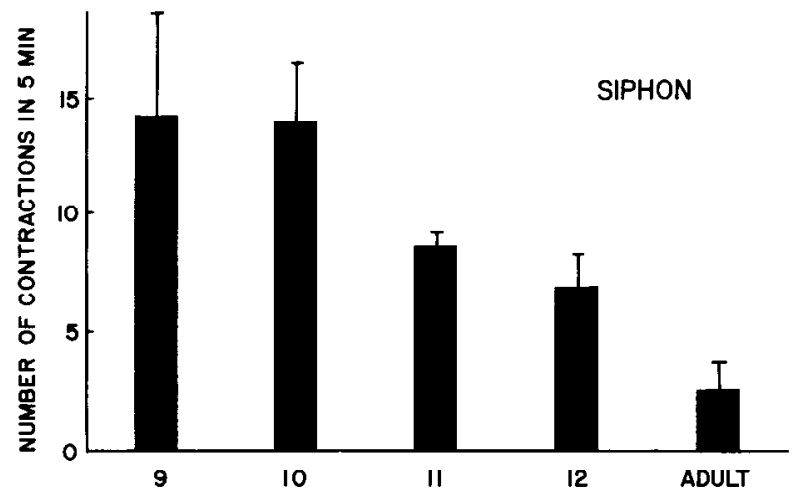

B

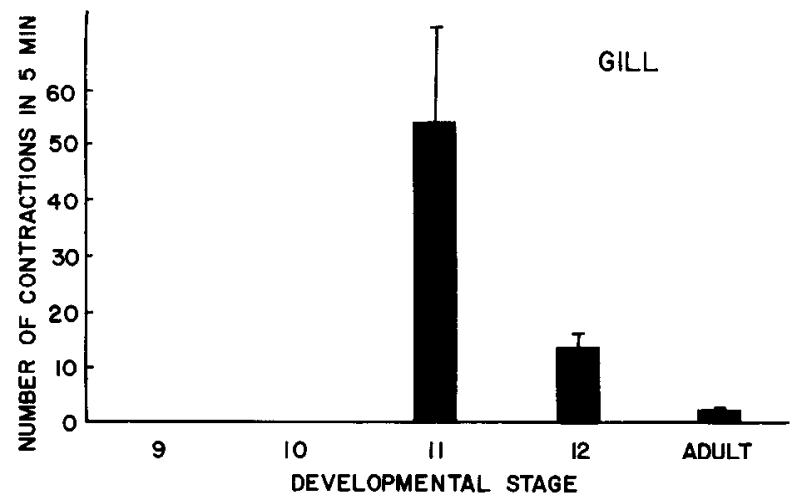

Figure 3. Spontaneous contractions of the siphon and gill. $A$, Mean number $( \pm$ SEM) of spontaneous siphon contractions observed in $5 \mathrm{~min}$ for stages 9 to adult ( $n=5$ for each stage). There is an initial high rate of spontaneous contractions in stages 9 and 10 that progressively decreases with later developmental stages. $B$, Mean number $( \pm \mathrm{SEM})$ of spontaneous gill contractions observed in $5 \mathrm{~min}$ for juvenile stages 11 to adult ( $n=5$ for each stage). There is an initial high rate of spontaneous gill contractions in stage 11 (higher in rate than the highest siphoncontraction rate) (note ordinate scale differences in $A$ and $B$ ), which decreases with later developmental stages. Only full gill contractions (not twitches) were scored (see text).

siphon contraction and the gill contraction closest to it in time was computed. These intervals were pooled into a composite interval histogram. Concurrence for evoked contractions was scored by analyzing videotapes of evoked siphon contractions and determining the number of gill and siphon contractions that occurred within $1 \mathrm{sec}$ of stimulus delivery.

Statistical analysis. Within-group and between-group differences were assessed by means of $t$ tests for correlated or independent means, respectively. When more than 2 groups of animals were used in an experiment, initial overall significance was determined by a one-way ANOVA, followed by Newman-Keuls planned comparisons (Winer, 1962). All probability values are 2-tailed. All data are expressed in terms of means, and, where between-group comparisons are made, variance is expressed as the SEM. In cases where nonparametric statistics were appropriate for the analysis, $\chi^{2}$ and Mann-Whitney $U$ tests (Siegel, 1956) were employed.

\section{Results}

Developmental characteristics of gill and siphon

To assess the development of both spontaneous and reflex control over the mantle organs, the animals were restrained for videotaping as shown in Figure 1 (see Materials and Methods for details).
Since the focus of the present studies was on the development of the gill and siphon withdrawal, particular attention was paid to characterizing the features of these organs at different developmental stages. The morphological features of the siphon and the gill at different stages of development are illustrated in Figure 2. For each stage the siphon and gill were traced from stopframe videotape records (see Materials and Methods).

Stage 9 . The siphon primordium is first clearly visible at this stage in the form of a ciliated crescent of mantle tissue approximately $8-10 \mu \mathrm{m}$ in width and $75 \mu \mathrm{m}$ in total length. At this stage the gill has not yet developed.

Stage 10. The siphon is larger, about $130 \mu \mathrm{m}$ in diameter and approximately $250 \mu \mathrm{m}$ in total length. There is a row of 5-10 clearly separated white spots around the rim of the siphon. The gill primordium first appears at this stage but is obscured from view by the mantle and the shell.

Stage 11. The siphon has grown much larger, having a diameter of about $220 \mu \mathrm{m}$ and a total length of approximately $350 \mu \mathrm{m}$. An increased number of white spots are now fused and appear as a white edge on the rim of the siphon. The gill now protrudes from under the shell and is about $460 \mu \mathrm{m}$ in length.

Stage 12. The siphon is now about $650 \mu \mathrm{m}$ in diameter and projects approximately $800 \mu \mathrm{m}$ out from the shell when relaxed. At this stage the siphon begins to take on the 3-dimensional funnellike shape characteristic of the adult. The gill pinnules are more developed than in stage 11 , and the gill itself is much larger, close to $2000 \mu \mathrm{m}$ in length (measured along the anteriorposterior axis).

Adult. The mantle organs of the adult are considerably larger than those of the juvenile: The relaxed siphon measures about $30 \mathrm{~mm}$ in diameter, and the gill is about $75 \mathrm{~mm}$ in length.

The mantle organs of Aplysia display 2 basic classes of behaviors: (1) a fixed action pattern characterized by spontaneous contractions and (2) reflex contractions in response to tactile stimuli.

\section{Spontaneous contractions}

\section{Frequency of siphon and gill contractions}

Spontaneous contractions of the siphon were exhibited by every juvenile stage studied, from the first appearance of the siphon in stage 9 to the mature adult. A comparison between freely moving and restrained adult animals showed that restraint significantly increased the frequency of spontaneous contractions. Freely moving animals $(n=5)$ showed a mean of 0.17 spontaneous contractions/min, while the same animals, once restrained and rested for $60 \mathrm{~min}$ prior to observation, exhibited a mean of 0.49 contractions $/ \min \left(t_{(4)}=6.0, p<0.001\right)$. Thus, consistent with the previous observations of Kanz et al. (1979), restraint significantly increased the frequency of occurrence of this fixed action pattern.

As in the adult, when spontaneous siphon contractions were observed in unrestrained juvenile animals fewer contractions were observed for each stage than were recorded in restrained animals. Since restraint was required for viewing gill contractions, and 1 goal of this experiment was to compare gill and siphon responses directly, our analysis of spontaneous contractions was carried out in restrained animals. In examining spontaneous siphon contractions at different developmental stages, a clear developmental trend emerged in terms of the rate of spontaneous contractions: Young juvenile animals (stages 9 and 10) exhibited the highest rate of contractions, and there was a 
progressive and significant decrease in this rate with subsequent developmental stages $(\mathrm{F}(4,20)=4.065, p<0.01$; Fig. $3 A)$. Although we have not systematically examined it, we have observed a comparable developmental trend in unrestrained animals.

The gill develops in stage 10 as a small bud usually hidden underneath the mantle and the shell (see Fig. 2). By stage 11 the gill is more readily visualized. Therefore, the first stage in which we studied the gill was stage 11 . In this stage the developing gill exhibits 2 kinds of spontaneous contractions, highfrequency twitches and lower-frequency full contractions.

High-frequency gill twitches. These gill contractions occurred at a very high rate (mean $131.1 \pm 10.3 / \mathrm{min}$ ) and were characterized by twitchlike contractions of the gill (relative ampliıude 1; see Materials and Methods). These twitches were highly correlated (often 1:1) with the occurrence of each heartbeat in the animal (which could readily be measured since the heart is easily visualized through the animal's body wall). Moreover, when the heart showed prolonged periods of inhibition (up to $5 \mathrm{sec}$ ), the high-frequency gill twitches would cease as well. Finally, surgical removal of the gill, leaving it attached to the abdominal ganglion, immediately abolished these twitchlike contractions but not the lower-frequency full contractions (described below). Thus, it is likely that the high-frequency twitches are not active contractions of the gill but rather are the passive reflections of hemolymph being pumped through the gill with each heartbeat. These twitches disappear by late stage 11, perhaps reflecting morphological changes in the gill (such as thickening or stiffening of the pinnules) that would reduce passive movements of the tissue.

Full gill contractions. These spontaneous gill contractions (relative amplitude scores of 2 or 3 ) occurred at a much lower rate (about $11 / \mathrm{min}$ ) than the twitches (relative amplitude score of 1) described above, but at a substantially higher rate than the spontaneous siphon contractions described earlier (Fig. $3 A$ ). Following the same pattern as the siphon, the frequency of these spontaneous gill contractions diminished progressively and significantly across developmental stages (stages 11,12 , and adult: $\mathrm{F}(2,12)=7.13, p<0.01$ ). By stage 12 (over a period of about 4 weeks), there was a reduction from a mean of $11 / \mathrm{min}$ (stage 11) to a mean of $2.8 / \mathrm{min}$, and in the adult they were reduced even further, to a mean of $0.49 / \mathrm{min}$ (Fig. $3 B$ ).

\section{Concurrence of siphon and gill contractions}

In adult animals the siphon and gill contract together during spontaneous contractions. This can be quantified in terms of a concurrence score in which the percentage of cocontractions of the siphon and gill (defined as occurring within $1 \mathrm{sec}$ of each other) is expressed as a percentage of the total number of spontancous contractions occurring during a $15 \mathrm{~min}$ obscrvation period. Thus, a concurrence score can range from $0.0 \%$ (no cocontraction) to $100 \%$ (complete concurrence). (For details, see Materials and Methods.) We found that there was a progressive increase in the concurrence score of siphon and gill contractions with increased developmental stages (Fig. 4). In adults $(n=5)$, the average concurrence score for gill and siphon during spontaneous contractions was quite high, $85.7 \%$. Given the known adult circuitry for spontaneous contractions (see Discussion), one might expect the adult concurrence score to be $100 \%$. With our scoring procedures each component (siphon and gill) was scored independently and blind. With this pro-

\section{SPONTANEOUS CONTRACTIONS}

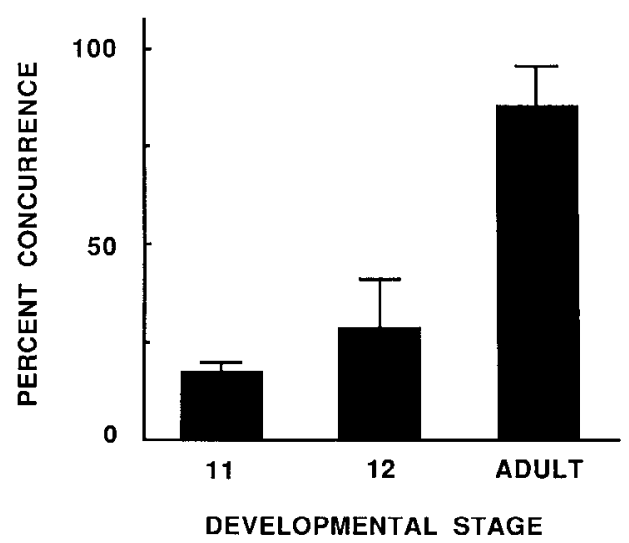

Figure 4. Concurrence of siphon and gill spontaneous contractions. Percentage of concurrent contractions of siphon and gill during spontaneous contractions is shown in juvenile stages 11 to adult. Concurrence was defined as the percentage of siphon and gill contractions occurring within $1 \mathrm{sec}$ of one another. (See Materials and Methods for details. $n=5$ for each stage.)

cedure any additional contraction of either organ not related to the fixed action pattern would contribute to a lower net concurrence score. Thus, our measure provides a conservative, lower-limit cstimatc of adult concurrence.

In contrast to adults, in stage 12 animals $(n=5)$ the average concurrence was only $28.6 \%$, and, in stage 11 animals $(n=5)$, $17.2 \%$. An ANOVA revealed a highly significant trend towards greater concurrence of spontaneous contractions with older developmental stages $(\mathrm{F}(2,12)=36.9, p<0.0002)$. Subsequent planned comparisons showed that both stage 11 and 12 animals had a significantly lower concurrence of contractions than did adult animals ( $p<0.01$ in each case).

This increase in concurrence score between spontaneous siphon and gill contractions (Fig. 4) suggests that the 2 events become progressively more likely to occur together; that is, they become more synchronized during development. However, since the spontaneous contractions of the siphon and gill occur at different rates early in development (Fig. 3), the possibility existed that the increase in concurrence score we observed did not reflect a progressive increase in synchronization of the 2 kinds of contractions, but rather reflected the progressive decrease in the rate of gill contractions. For example, siphon contractions (which occur at a much lower rate than gill contractions) might be perfectly synchronous (i.e., occur 1:1) with gill contractions, even in stage 11 , but additional gill contractions occurring at this stage would cause the concurrence score to be low compared with later stages, when the rate of gill contractions is decreased. To examine this possibility for stages 11,12 , and adult, we generated a composite histogram expressing the distribution of intervals between each spontaneous siphon contraction and the gill contraction closest to it in time (see Materials and Methods). The number of observations for each animal within a stage was similar; thus, the total observations for all animals within a stage were pooled to form composite histograms for stages 11 , 12, and adult (Fig. 5). The total number of observations decreased from stage $11(n=127)$ to stage $12(n=96)$ to adult $(n=32)$ due to the decrease in the rate of spontaneous contractions across development (Fig. 3). 

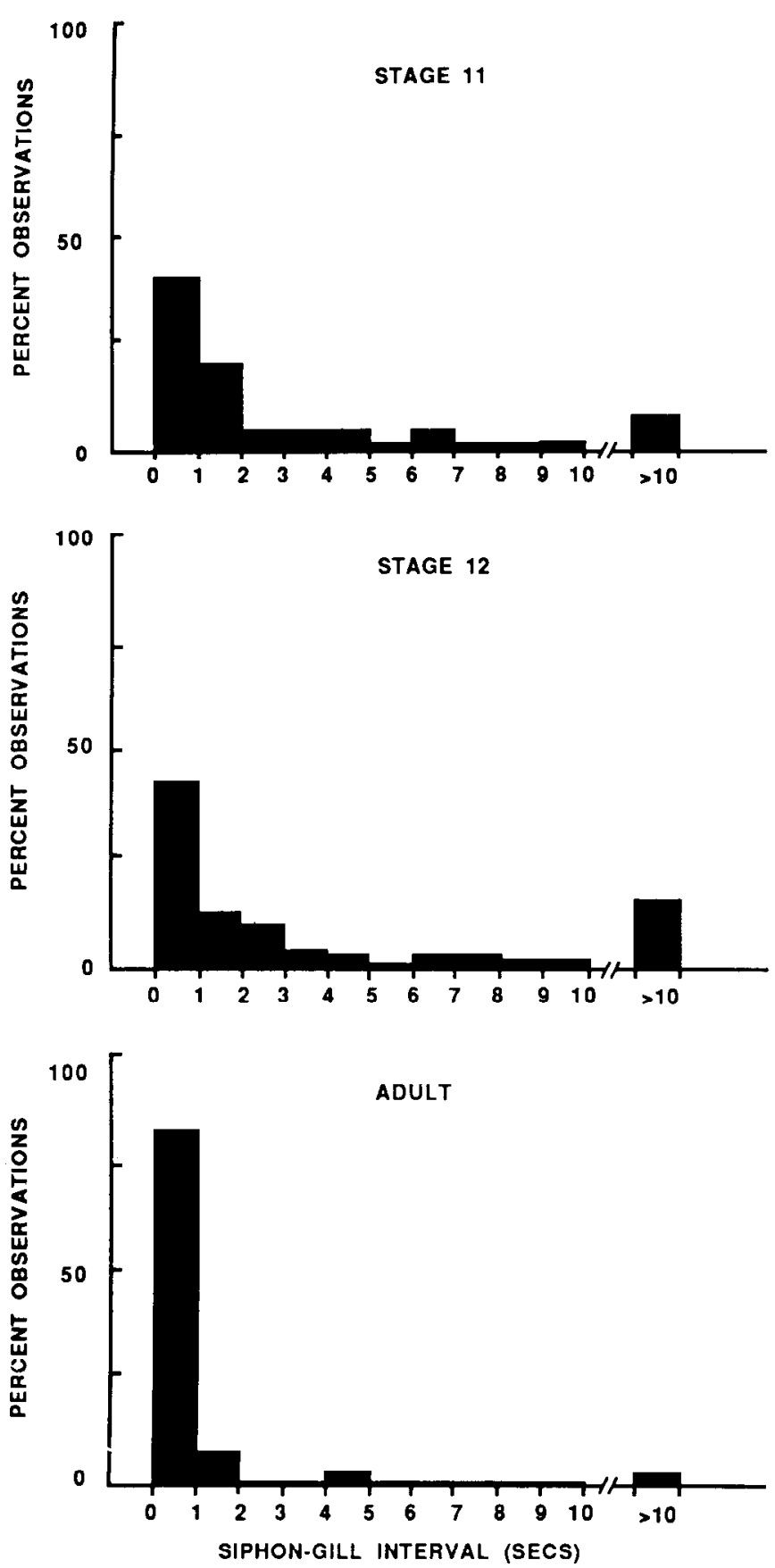

Figure 5. Increased functional coupling of siphon and gill during development. Composite histograms for stage 11,12, and adult animals show the distribution of intervals (in sec) between each spontaneous siphon contraction and the gill contraction closest to it in time. The pronounced shift to the left in older animals indicates a significant developmental trend toward shorter intervals between siphon and gill contractions from stage 11 to adult, demonstrating increased functional coupling of the 2 effector organs (see text).

If the siphon and gill contractions are equally well coupled at all 3 developmental stages, the histograms for each stage should have comparablc distributions. On the other hand, if synchronization between siphon and gill contractions actually increases with development, the proportion of short intervals between these 2 events should increase in later developmental stages. The histograms in Figure 5 indicate a significant trend toward shorter intervals between siphon and gill contractions with subsequent developmental stages. In stage $11,41 \%$ of the observed siphon contractions fell within $1 \mathrm{sec}$ of a gill contraction and were therefore concurrent by our criterion. This percentage increased slightly to $43 \%$ in stage 12 and dramatically to $84 \%$ in the adult stage (Fig. 5). Thus, the proportion of observations falling in the concurrent $(1 \mathrm{sec})$ bin significantly increases across developmental stages ( $\chi^{2}$ with $2 d f=20.7, p<0.001$ ). These data reveal 2 important facts: First, there is measurable coupling of siphon and gill contractions even as early as in stage 11 animals (complete lack of coupling would be reflected by a uniform or flat distribution across all intervals, which was not the case; see Fig. 5). Second, the coupling between siphon and gill contractions significantly increases in later developmental stages, as shown by the pronounced shift toward very short intervals in the adult.

In summary, early in juvenile development the gill and siphon both exhibit spontancous contractions as soon as each organ develops. However, initially the contractions are only moderately synchronized. Over a period of several weeks the 2 organs take on the adult form of cocontraction.

\section{Evoked contractions}

The second major class of behavioral response exhibited by the mantle organs is a reflex contraction of the gill, siphon, and mantle shelf in response to tactile stimulation. One of the most sensitive receptive fields for this reflex is the siphon itself. We have examined the development of the gill and siphon withdrawal components of this reflex in stage 9-12 animals and compared the response characteristics at each stage with the adult form of the reflex.

\section{Input-output relationship}

In adult animals the withdrawal reflex shows a monotonic graded increase in response as a function of increasing stimulus intensity (e.g., see Carew and Kandel, 1977). Thus, a relevant concern in characterizing the development of the withdrawal reflex was specifying the relationship between stimulus intensity and response amplitude at different developmental stages. Specifying this relationship is important for 2 reasons. First, it provides important normative descriptive data to assess similarities or differences in the reflex at different stages. Second, it provides a means of equating the functional intensity of stimuli in different developmental stages, which is essential for the analysis of the development of learning in this reflex (see Rankin and Carew, 1987). To investigate this question, we focused on the siphon withdrawal component of the reflex because it can be measured at the earliest stages of development. Stages 9-11 were studied. Three animals at each stage were restrained (Fig. 1) and run 1 at a time. The intensity of water jet stimuli delivered to the siphon was systematically varied by increasing or decreasing the distance of the pipette tip from the siphon (see Materials and Methods). For each stimulus intensity, 2 stimuli were delivered at temporal intervals that would produce no behavioral decrement, and the response magnitudes to the 2 stimuli were averaged to provide an estimate of response amplitude at that intensity. Both an increasing and a decreasing scrics of stimulus intensities were run for each animal. The data from the ascending series are shown in Figure 6. Although there was a tendency for the responses of stage 9 animals to be slightly lower at all stimulus intensities, the average slopes of the curves for 


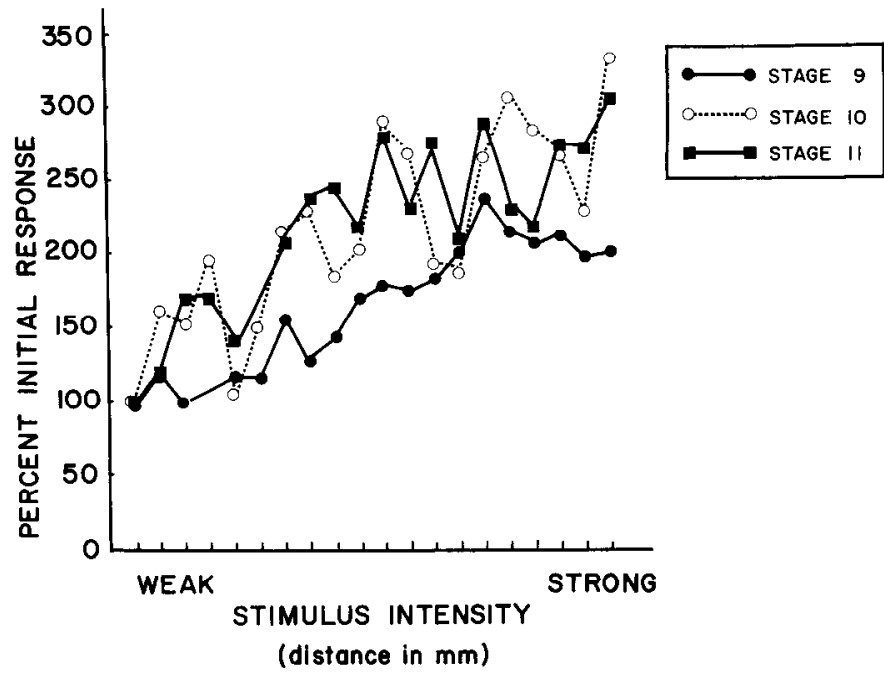

Figure 6. Intensity-response relationship for the siphon withdrawal reflex. Intensity-response curves for siphon reflex amplitude are shown as a function of increasing stimulus intensity for juvenile stages 9-11 ( $n=3$ for each stage). The slopes of the curves for all 3 stages are qualitatively very similar and parallel, indicating that at all developmental stages the siphon withdrawal reflex appears to be graded as a monotonic function of stimulus intensity. Stimulus intensities ranged from $1 \mathrm{mg}$ (weakest) to approximately $8 \mathrm{mg}$ (strongest). (See Materials and Methods.)

all 3 stages are qualitatively similar and roughly parallel, indicating that, as in the adult, at all developmental stages the reflex appears to be graded as a monotonic function of stimulus intensity.

\section{Concurrence of siphon and gill contractions}

In the adult the reflex consists of a short-latency coordinated contraction of the gill and siphon. A characteristic feature of this response is that the siphon and the gill invariably contract together.

As soon as the siphon primordium appears in stage 9 , it exhibits a brisk withdrawal reflex in response to a brief $(50 \mathrm{msec})$ jet of seawater. When the gill primordium first appears in stage 10 , it also immediately exhibits a clear withdrawal reflex in response to siphon stimulation. Thus, the afferent input from the siphon to this reflex withdrawal system appears to be functionally intact as soon as the effector organs differentiate. A striking feature of the development of this reflex system is that as soon as the reflex is intact, gill and siphon withdrawal resembles the adult form, that is, they cocontract in response to tactile input. Specifically, we found that during the withdrawal reflex the gill and siphon invariably exhibited a concurrence of $100 \%$, both in stage $11(n=5)$ and in stage $12(n=5)$, as well as in the adult $(n=5)$ (Fig. 7$)$.

To elicit siphon withdrawal in these experiments, we used a relatively weak tactile stimulus evoking a reflex of less than $50 \%$ of a maximum contraction. Thus, it is not likely that the invariant concurrence we observed was due to recruitment of siphon and gill contractions caused by strong stimulation. In fact, informal observations suggest that comparable invariant concurrence is obtained at all stimulus intensities, varying from just threshold to very strong stimuli.

Another important consideration is stimulus spread, since a local reflex of the gill could be elicited by spread of the water

\section{REFLEX CONTRACTIONS}

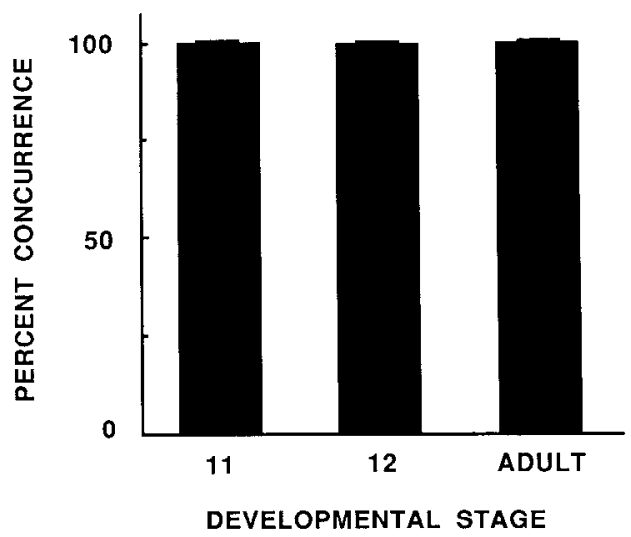

Figure 7. Concurrence of siphon and gill reflex contractions. Percentage concurrence of siphon and gill reflex contractions is shown following tactile stimulation of the siphon for stages 11 to adult ( $n=5$ per stage). In all stages the siphon and the gill invariable contracted together.

jet stimulus directly to the gill. If this were the case, the high concurrence we observed could reflect parallel activation of local siphon and gill reflexes. Two observations argue against this possibility: (1) the water jet stimulus was quite localized to the siphon and caused no passive deflection of the gill; and (2) when the abdominal ganglion was surgically removed (which would remove all central contribution to the reflex but leave the local reflexes of the gill intact), identical stimulus delivery produced a gill withdrawal response that was reduced by $95 \%$ (Nolen et al., 1987). Thus, stimulus spread does account for the $100 \%$ concurrence we observed.

The invariant concurrence of siphon and gill contractions during reflex responses as soon as the reflexes are intact, early in juvenile development (Fig. 7), is in marked contrast to the development of spontaneous contractions, which achieve the adult form of high concurrence only over a period of several weeks (Fig. 4). Thus, our results show that exogenous (reflex) control over the mantle organs develops according to a different ontogenetic timetable than endogenous ("spontaneous") control, acquiring the adult form much more rapidly.

\section{Contribution of CNS to siphon withdrawal}

A final important consideration concerned the relative contribution of the CNS to the siphon contractions we observed. In adult Aplysia it is known that the CNS (the abdominal ganglia) contributes about $55 \%$ to the total reflex response of the siphon elicited by tactile stimulation (Perlman, 1979). It was important for us to determine whether the CNS contributes at least as much to the siphon reflex response in juveniles as it does in adults, or whether the peripheral nervous system (PNS) might play a more significant role in developing animals (a comparable examination of central and peripheral contributions to gill withdrawal is examined in the third paper in this series, Nolen et al., 1987). To investigate this question, we examined the effects on both spontaneous and evoked siphon contractions of removing the CNS (the abdominal ganglia), which innervates the gill, siphon, and mantle shelf. Eighteen stage 11 juvenile animals were used. Half the animals served as the experimental group, having their abdominal ganglia surgically removed (deganglionated, $n=9$ ); the other half served as sham-operated controls 
SPONTANEOUS CONTRACTIONS

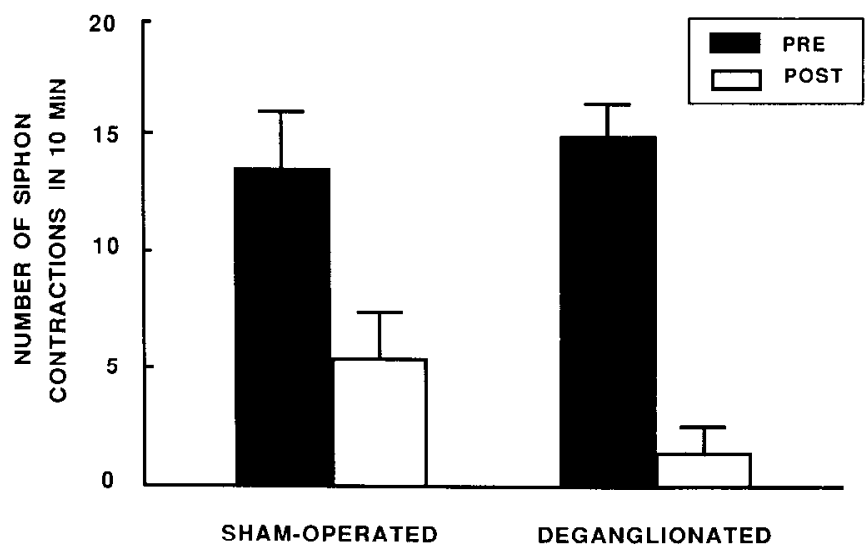

Figure 8. CNS contribution to spontaneous siphon contractions. A significant reduction in the number of spontaneous contractions after surgery was observed (in a $10 \mathrm{~min}$ period) for both sham-operated ( $n=$ $10)$ and deganglionated $(n=10)$ animals. The decrease in response number was significantly greater in deganglionated animals than in shamoperated animals $(p<0.05)$.

(sham-operated, $n=9$ ). (For details of surgery, see Materials and Methods.) The animals were run in pairs using a doubleblind procedure. First, an experimenter unaware of the experimental condition of the animals (deganglionated or sham-operated) restrained the animals, delivered the stimuli, and videotaped the responses. Second, another independent observer, also unaware of the treatment conditions, traced the responses for subsequent quantification.

All animals were restrained and rested $10 \mathrm{~min}$, videotaped in the absence of stimulation for $10 \mathrm{~min}$ to record spontaneous contractions, and then given 10 water jet stimuli (ISI of $1 \mathrm{~min}$ ) to the siphon to elicit reflex contractions. Following this treatment animals underwent surgery (either deganglionation or a sham operation) and, after a $1 \mathrm{hr}$ rest, they were again restrained and received an identical treatment regimen $(10 \mathrm{~min}$ rest, 10 min recording of spontaneous contraction, 10 water jet stimuli at an ISI of $1 \mathrm{~min}$ ).

\section{Spontaneous contractions}

Before surgery both groups of animals showed comparable numbers of spontaneous contractions during the $10 \mathrm{~min}$ observation period (sham-operated: $\bar{X}=13.7 \pm 2.4$ contractions; deganglionated: $\bar{X}=12.8+1.6$ contractions; Fig. 8, PRE). After surgery both groups showed a significant reduction in the number of spontaneous contractions (sham-operated: $\bar{X}=5.4 \pm 1.8$, $t_{8}=3.62, p<0.01$; deganglionated: $\bar{X}=1.4 \pm 1.2, t_{8}=7.77$, $p<0.005$; Fig. 8, POST). Therefore, some aspect of the surgery itself dramatically affected the occurrence of spontaneous contractions (see Discussion). An additional effect of deganglionation can be seen by comparing the postsurgery responsiveness of sham-operated and deganglionated animals. (As these scores were markedly non-normal in their distribution, a nonparametric between-group comparison, Mann-Whitney $U$ test, was used.) Deganglionated animals showed a significantly greater reduction in the number of spontaneous responses exhibited after surgery than did the sham-operated controls $(p<0.05)$.

\section{Evoked contractions}

From the standpoint of future cellular studies of the development of learning (see, for example, Nolen et al., 1987), a more
REFLEX CONTRACTIONS

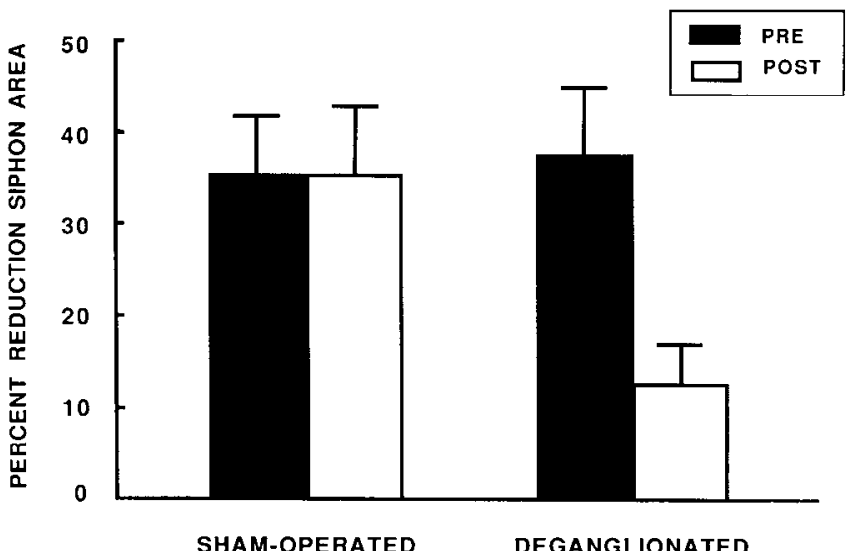

Figure 9. CNS contribution to reflex siphon contractions. The mean response amplitude for siphon withdrawal pre- and postsurgery for shamoperated $(n=8)$ and deganglionated $(n=8)$ stage 11 animals is shown. There was no change in response amplitude for sham-operated animals following surgery, whereas deganglionated animals showed a significant $(66 \%)$ decrease in response amplitude $(p<0.02)$ following removal of the abdominal ganglion.

significant question than the contribution of the CNS to spontaneous contractions was its contribution to reflex or evoked contractions. To examine this question, 10 reflex responses were evoked prior to surgery (ISI $=1 \mathrm{~min}$ ) and 10 more $1 \mathrm{hr}$ after surgery. Constant-intensity, weak water jet stimuli $(4 \mathrm{mg})$ were used to elicit the reflex. Since there was a small decrement in response amplitude over 10 trials, we will present results based on an analysis of the first reflex response before surgery and the first response after surgery.

The presurgery reflex response amplitude for both groups was comparable (sham-operated: $\bar{X}=35.6 \pm 6.29 \%$ reduction of siphon area; deganglionated: $\bar{X}=37.42 \pm 7.24 \%$; Fig. 9, PRE). After surgery, there was no change in response amplitude in the sham-operated group $(\bar{X}=35.6 \pm 7.15 \%)$ compared with their own preoperation scores. Thus, unlike spontancous contractions (Fig. 8), reflex contractions appeared unaffected by the surgical procedures per se. In contrast, there was a significant reduction in the reflex response in the deganglionated group compared with their own preoperation scores $\left(\bar{X}=12.73 \pm 4.04 \%, t_{7}=\right.$ $3.15, p<0.02$ ). Moreover, the deganglionated group showed a significantly reduced response amplitude compared with shamoperated controls $\left(t_{14}=2.78, p<0.02\right.$; Fig. 9). Since surgery produced no reduction in sham-operated controls, all of the reduction in reflex response amplitude observed in deganglionated animals can be attributed to the removal of the CNS. Deganglionation produced a decrease in the amplitude of siphon contractions from a mean $37.4 \%$ reduction in siphon area prior to surgery to a mean $12.7 \%$ reduction after surgery, or a net reduction in response amplitude of $66 \%$. Thus, using a water jet stimulus to elicit the response, the CNS contributes $66 \%$ to siphon reflex response amplitude in stage 11 juvenile Aplysia.

\section{Discussion}

\section{Endogenous control of siphon and gill withdrawal}

The siphon and gill of Aplysia emerge at different stages of juvenile development: The siphon appears approximately $4 \mathrm{~d}$ after metamorphosis (stage 9) and the gill approximately $7 \mathrm{~d}$ later (stage 10: Kriegstein et al., 1974; Kriegstein, 1977b). As 
soon as each organ emerges it exhibits spontaneous contractions. Howcver, these contractions are not yet organized into the stereotypic fixed action pattern characteristic of respiratory pumping in the adult, in which the gill and siphon, as well as the mantle shelf and parapodia, contract synchronously in all-ornone fashion (Byrne and Koester, 1978). Spontaneous siphon and gill contractions in the developing juvenile differ from those observed in the adult in 2 ways: the rate of spontaneous contractions is higher, and the siphon and gill exhibit much less concurrence of contraction.

When the siphon first appears in stage 9 it exhibits a relatively high rate of spontaneous contraction (about $2.8 / \mathrm{min}$ ), which diminishes significantly as development progresses. When the gill emerges in stage 10 , it exhibits 2 kinds of spontaneous contractions: (1) high-frequency $(131.1 / \mathrm{min})$ twitches that are most readily explained as passive reflections of hemolymph being pumped through the gill (since the twitches are almost 1:1 with heartbeat and disappear when the heart and gill are surgically disconnected); and (2) lower-frequency, full contractions. These contractions occur at a substantially higher rate (about $11 / \mathrm{min}$ ) than the spontaneous siphon contractions observed in stage 9. Both gill and siphon contractions exhibit a significant reduction in spontaneous rate across developmental stages.

Thus, it appears that each organ (siphon and gill) goes through its own phase of high rate of spontaneous contractions that gradually diminishes with age. Furthermore, this sequence of diminishing frequency appears to occur independently for the 2 organs, since the frequency of spontaneous siphon contractions is substantially diminished by stage 11 , a stage when the frequency of spontaneous gill contractions is highest. The occurrence of high spontaneous activity in the juvenile siphon and gill may reflect a number of possible factors in the developing effector systems, including hypersensitivity of the neuromuscular junction and/or high firing rate of the motor neurons. Finally, high spontaneous activity may be a general feature of developing effector systems, as it is often observed in both vertebrates and invertebrates (Anggard et al., 1961; Hamberger, 1963; Hamberger et al., 1966; Berrill, 1973; Kammer and Kinnamon, 1979; for a general review, see Bekoff, 1981).

The characteristic synchrony of contractions of the mantle organs during spontaneous contractions in the adult is in contrast to the lower rate of concurrence of siphon and gill contractions in early stages of juvenile development. The concurrence of contractions of the mantle organs develops over a period of several weeks, assuming the adult form late in stage 12 (approximately 60-90 d after metamorphosis).

The adult neural circuit underlying spontaneous respiratory pumping movements has been studied extensively. Originally, the interneurons responsible for the spontaneous contractions of the mantle organs were collectively called "Interneuron II" (Frazier et al., 1967). Byrne and Koester (1978) then characterized many of the circuit elements controlling respiratory pumping. Subsequently, Byrne (1983) and Koester (1983) have identified 2 clusters of interneurons, the L25 and R25 clusters, respectively, that are the central command elements responsible for the pattern generation underlying respiratory pumping. Neurons within these clusters are electrically coupled both to each other and to neurons in the other cluster (Koester, 1983). Moreover, cells in these clusters make extensive, direct synaptic connections to numerous gill and siphon motor neurons. In addition to generating spontaneous bursts of action potentials that produce respiratory pumping, tactile input to the siphon can trigger

\section{STAGE 9}

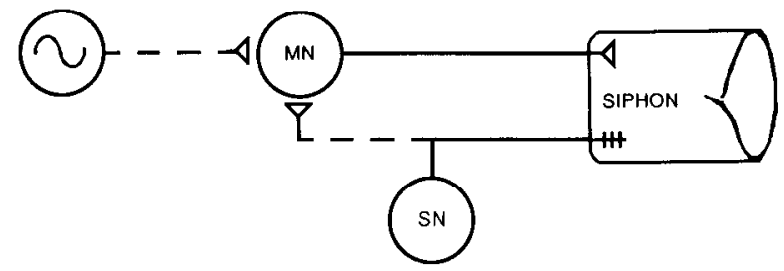

STAGES $\quad 10-11$
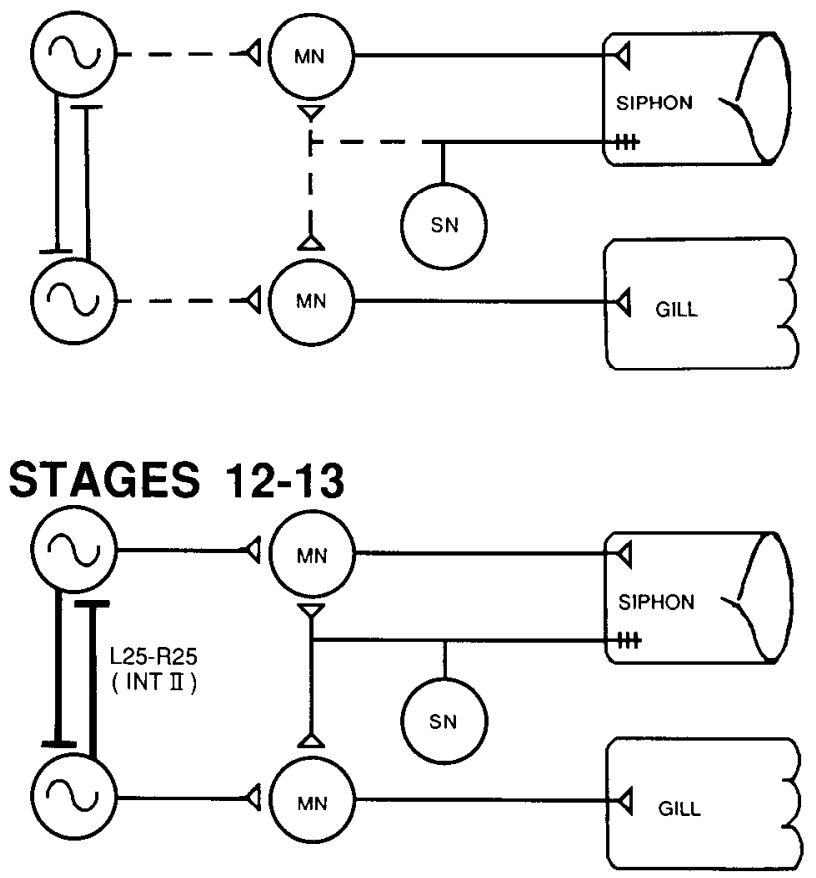

Figure 10. Hypothetical model for fixed action pattern and reflex development. Hypothetical model for the development of neural circuits underlying the emergence of endogenously triggered spontaneous contractions (left side) and exogenously triggered reflex contractions (right side) of siphon and gill. Dashed lines indicate functional (as opposed to monosynaptic) connections. For stages 10-11, thin lines connecting spontaneous drivers of the siphon and gill motor neurons represent weak electrical coupling. For stages 12-13, heavy lines between spontaneous drivers represent strong electrical coupling (see text).

action potentials in L25-R25 cells that lead to reverberatory excitatory activity in the rest of the network, culminating in a regenerative burst (Byrne, 1983; Koester, 1983). Thus, as emphasized by Pinsker and colleagues (Kanz et al., 1979), respiratory pumping can be triggered by tactile input and thus can play a significant role in the defensive gill and siphon withdrawal reflex.

Given the known circuitry underlying respiratory pumping, how might this circuit be assembled during development? Our behavioral data provide the basis for a speculative model, as shown in Figure 10. In stage 9 animals, the siphon exhibits recurrent spontaneous contractions, which we hypothesize may be produced by one subcomponent of the mature L25-R25 (Interneuron II) complex. In stages 10 and 11 , the gill emerges and displays recurrent spontaneous contractions that are only weakly correlated with spontaneous siphon contractions. We hypothesize that these contractions may be produced by another subcomponent of the mature interneuronal complex. Two interrelated lines of evidence support the notion that, in stages 10 
and 11 , the 2 subcomponents are relatively independent: (1) spontaneous siphon and gill contractions occur at very different rates during these stages; and (2) the concurrence of contractions of the siphon and gill in these stages is lower than in the adult. In stages 12 and 13 (adult), we hypothesize that the 2 subcomponents become functionally more tightly coupled to form the mature L25-R25 complex. Since most of the known connectivity among the cells in the L25 and R25 clusters is electrical, we speculate that the high degree of synchrony of the siphon and gill during spontaneous contractions shown by adult animals is achieved by electrotonic coupling between the 2 subcomponents.

Clearly this model is speculative and rests upon several assumptions. For example, it assumes that the spontaneous contractions exhibited by the juvenile siphon and gill are the anlage of adult respiratory pumping. This need not be the case. A less parsimonious possibility is that the concurrent spontaneous contractions in the juvenile could be mediated by other interneuronal networks than those responsible for respiratory pumping in the adult. Moreover, the model assumes that spontaneous contractions in the juvenile are centrally mediated, as they are in the adult (Kupfermann and Kandel, 1969; Peretz, 1969; Kupfermann et al., 1974). Our experiments with removing the CNS did reveal a significant central contribution to spontaneous siphon contractions. However, these same experiments showed that the surgical procedures per se significantly reduced the incidence of spontaneous contractions. We do not know what aspect of the surgery reduced the spontaneous rate in juveniles, but one possibility is that spontaneous contractions are triggered by some factor in the hemolymph (Kanz and Quast, 1985) and that surgery compromises the circulatory system, thus decreasing the number of spontaneous contractions. This would explain why reflex contractions of the mantle organs were unaffected by the identical surgical procedure (see below).

In summary, the speculative model we have proposed has 2 attractive aspects: (1) it can account for the principal features of development of endogenous control of the siphon and gill; and (2) the assumptions underlying the model can be directly tested by means of intra- and extracellular recording from the intact and isolated CNS at different juvenile stages (see, for example, Nolen et al., 1987).

\section{Exogenous control of siphon and gill withdrawal}

In contrast to endogenous (spontaneous) control of the siphon and gill, which takes several weeks to mature, we have found that exogenous (reflex) control over these organs is intact and resembles the adult form as soon as each organ emerges at its respective developmental stage. Like the reflex in adults, the amplitude of siphon contractions is graded as a function of stimulus intensity. Moreover, throughout development, gill and siphon show a high degree of concurrence during reflex contractions, which is a characteristic feature of the reflex in adult animals. In fact, the gill and siphon invariably cocontract in response to siphon stimulation, even at the earliest juvenile developmental stages.

An important issue concerned the relative contribution of the CNS and PNS to reflex contractions in juvenile animals. In adults the CNS contributes about $55 \%$ to the total reflex response of the siphon elicited by tactile stimulation (Perlman, 1979). The remaining $45 \%$ is contributed at least in part by an identified cluster of motor neurons located peripherally along the siphon nerve (Bailey et al., 1979). Compared with its contribution to siphon withdrawal, the CNS contributes significantly more (about 90\%) to gill withdrawal under appropriate stimulus conditions in the adult (Carew et al., 1979). We found that the CNS in juveniles made a comparable (actually slightly larger) contribution to reflex siphon contractions $(66 \%)$ as in adults. Moreover, as in the adult, the gill withdrawal component of the reflex also has a highly significant central contribution (approximately 95\%) in juvenile development (Nolen et al., 1987). We should emphasize that estimates of the central contribution for both siphon and gill withdrawal have been obtained using controlled, quantifiable water jet stimuli to the siphon. This is important because the contribution of the CNS to the withdrawal reflex may in part depend on the type of stimulus utilized to trigger the reflex (Peretz et al., 1976; Carew et al., 1979). In summary, our observations suggest that the reflex withdrawal of the gill and siphon in juvenile animals has central contributions comparable to those in the adult, lending further support to the idea that the reflex system is mature quite early in its ontogeny.

Our results in examining the development of the reflex withdrawal system suggest further features of the model we propose in Figure 10. In stage 9 the siphon withdrawal reflex is already intact, suggesting the possibility that the identified LE sensory neurons known to mediate this reflex in the adult (Castellucci et al., 1970; Byrne et al., 1978) may already make functional connections to siphon motor neurons. In the adult these connections are known to be both monosynaptic and polysynaptic to siphon motor neurons. However, for these early developmental stages we simply posit a functional connection (without implying monosynapticity) between sensory neurons and motor neurons. In stages 10-11 the gill emerges and both gill and siphon components of the reflex are intact, suggesting the possibility that the LE sensory neurons also make functional connections to gill motor neurons in these stages. This postulated dual connectivity of the siphon sensory neurons to both siphon and gill motor neurons (which is known to occur in the adult) could account for the invariant cocontraction of the siphon and gill that is characteristic of reflex contractions at these developmental stages. Finally, it is postulated that in stages 12 and 13 , when the adult form is achieved, a significant portion of the reflex is mediated by monosynaptic input from LE sensory neurons (Castellucci et al., 1970). It is also known that, in the adult, sensory input from the siphon can trigger a burst from the L25R25 (Interneuron II) complex, thus triggering gill and siphon withdrawal (Kanz et al., 1979). Thus, another important question that warrants further study concerns the stage, or stages, in development when LE sensory input functionally connects to the L25-R25 complex.

Taken collectively, our results show that endogenous (spontaneous) control of the mantle organs emerges according to a different devclopmental timetable than does exogenous (reflex) control. The fixed action pattern develops slowly over a period of several weeks, whereas the reflex is intact immediately, as soon as the organs emerge. Similar temporal dissociation in the development of fixed action patterns and reflexes that utilize common effector structures has been observed in other invertebrate animals. For example, in the hawkmoth Manduca sexta, the fixed action responsible for ecdysis is intact and functional prior to a reflex (the gin trap reflex) that is appropriate only at one particular developmental stage (Truman, 1980; Levine and Truman, 1983). Moreover, as in Aplysia, the reflex appears functional immediately, requiring only the presence of eclosion hormone for its expression (Levine and Truman, 1983). However, 
the temporal order observed in Manduca has the opposite pattern of what we observe in Aplysia, where the mature reflex precedes the fixed action pattern. Thus, the order of temporal emergence of particular behaviors during development may depend less on their form (e.g., reflex or fixed action pattern) and more on their adaptive significance at a particular developmental stage.

This raises the question of the functional significance of the developmental scheme we observe in the mantle organs of Aplysia. It may be that the fixed action pattern (respiratory pumping) becomes functionally important for the animal only as other organs, such as the parapodia and mantle shelf, also develop. These organs are recruited into a stereotypic contraction during spontaneous pumping and serve to funnel seawater across the gill and out the siphon, presumably to facilitate respiratory exchange. In early juvenile stages, considerable respiratory exchange probably occurs across the skin, reducing the necessity of spontancous pumping until the gill becomes the principal respiratory organ later in development. In contrast to this fixed action pattern involving the mantle organs, reflex contractions of the mantle organs may be of prime importance as soon as the organs emerge. Since the siphon and gill become progressively more exposed as they develop, an intact and developmentally mature withdrawal reflex may have a high adaptive value from the outset.

In parallel to the developmental sequences involved in the functional assembly of siphon and gill withdrawal that we have described in this paper, there is a second developmental sequence involving the temporal emergence of different forms of learning and memory in this same reflex system. This developmental sequence is discussed in the second paper of this series (Rankin and Carew, 1987).

\section{References}

Anggard, L., R. Bergstrom, and C. G. Berhard (1961) Analysis of prenatal spinal reflex activity in sheep. Acta Physiol. Scand. 53: 128136.

Bailey, C. H., V. Castellucci, J. Koester, and E. R. Kandel (1979) Cellular studies of peripheral neurons in siphon skin of Aplysia californica. J. Neurophysiol. 42: 530-557.

Bekoff, A. (1981) Embryonic development of the neural circuitry underlying motor control. In Studies in Developmental Neurobiology, W. M. Cowan, ed., Oxford U. P., Oxford, UK.

Bentley, D. R., and R. Hoy (1970) Postembryonic development of adult motor patterns in crickets: A neural analysis. Science 170: 14091411 .

Berrill, M. (1973) The embryonic behavior of certain crustaceans. In Behavioral Embryology, G. Gottlieb, ed., Academic, New York.

Byrne, J. H. (1980) Neural circuit for inking behavior in Aplysia californica. J. Neurophysiol. 43: 896-911.

Byrne, J. (1983) Identification and initial characterization of a cluster of command and pattern-generating neurons underlying respiratory pumping in Aplysia californica. J. Neurophysiol. 42: 530-557.

Byrne, J., and J. Koester (1978) Respiratory pumping: Neuronal control of a centrally commanded behavior in Aplysia. Brain Res. 143: 87-105.

Byrne, J., V. Castellucci, and E. R. Kandel (1978) Contribution of individual mechanoreceptor sensory neurons to defensive gill-withdrawal reflex in Aplysia. J. Neurophysiol. 41: 418-431.

Carew, T. J. (1986) Advances in the cellular analysis of learning in Aplysia. In Cellular Basis of Learning: Dahlem Konferenzen, J.-P. Changeux and M. Konishi, eds., Springer, New York (in press).

Carew, T. J., and E. R. Kandel (1977) Inking in Aplysia californica. I. The neural circuit of an all-or-none behavioral response. J. Neurophysiol. 40: 692-707.

Carew, T. J., V. Castellucci, J. H. Byrne, and E. R. Kandel (1979) A quantitative analysis of the relative contribution of central and pe- ripheral neurons to the gill-withdrawal reflex in Aplysia. J. Neurophysiol. 42: 497-509.

Carew, T. J., E. T. Walters, and E. R. Kandel (1981) Classical conditioning in a simple withdrawal reflex in Aplysia. J. Neurosci. 1: $1426-1437$.

Carew, T. J., R. D. Hawkins, and E. R. Kandel (1983) Differential classical conditioning of a defensive withdrawal reflex in Aplysia californica. Science 219: 397-400.

Carew, T. J., C. H. Rankin, and M. Stopfer (1985) Development of learning and memory in Aplysia: I. Functional assembly of the gill and siphon withdrawal reflex. Soc. Neurosci. Abstr. 11: 643 .

Carew, T. J., E. Marcus, T. G. Nolen, and C. H. Rankin (1986) Contribution of central neuronal circuits to reflex gill and siphon withdrawal and simple forms of learning in developing Aplysia. Soc. Neurosci. Abstr. 12: 398.

Castellucci, V. F., I. Kupfermann, H. Pinsker, and E. R. Kandel (1970) Neuronal mechanisms of habituation of the gill withdrawal reflex in Aplysia. Science 67: 1445-1448.

Castellucci, V. F., E. R. Kandel, J. H. Schwartz, F. O. Wilson, A. C. Nairn, and P. Greengard (1980) Intracellular injection of the catalytic subunit of cyclic AMP-dependent protein kinase simulates facilitation of transmitter release underlying behavioral sensitization in Aplysia. Proc. Natl. Acad. Sci. USA 77: 7492-7496.

Cleary, L. J., and I. H. Byrne (1985) Interneurons contributing to the mediation and modulation of the tail-withdrawal reflex in Aplysia. Soc. Neurosci. Abstr. 11: 642.

Davis, W. J., and K. B. Davis (1973) Ontogeny of a simple locomotor system: Role of the periphery in the development of central nervous circuitry. Am. Zool. 13: 409-425.

Frazier, W. T., E. R. Kandel, I. Kupfermann, R. Waziri, and R. E. Coggeshall (1967) Morphological and functional properties of identified cells in the abdominal ganglion of Aplysia californica. J. Neurophysiol. 30: 1288-1351.

Fricke, R. A. (1984) Development of habituation in the crayfish due to selective weakening of electrical synapses. Brain Res. 322: 139143.

Hamberger, V. (1963) Some aspects of the embryology of behavior. Q. Rev. Biol. 38: 342-365.

Hamberger, V. (1968) Emergence of nervous coordination. Origins of integrated behavior. Dev. Biol. [Suppl.] 2: 251-271.

Hamberger, V., E. Wenger, and R. Oppenheim (1966) Motility in the chick embryo in the absence of sensory input. J. Exp. Zool. 162: 133160.

Hawkins, R. D., T. W. Abrams, T. J. Carew, and E. R. Kandel (1983) A cellular mechanism of classical conditioning in Aplysia: Activitydependent amplification of presynaptic facilitation. Science 219:400405.

Hawkins, R. D., G. A. Clark, and E. R. Kandel (1986) Cell biological studies of learning in simple vertebrate and invertebrate systems. In Handbook of Physiology, Section I. The Nervous System. Vol. 6. Higher Functions of the Nervous System. F. Plum, ed., American Physiological Society, Bethesda, MD (in press).

Hening, W. A., E. T. Walters, T. J. Carew, and E. R. Kandel (1979) Motor neuronal control of locomotion in Aplysia. Brain Res. 179 . 231-253.

Immelmann, K. (1969) Song development in the zebra finch and other estrildid finches. In Bird Vocalizations, R. A. Hilde, ed., Cambridge U. P., Cambridge, UK.

Jacob, M. H. (1984) Neurogenesis in Aplysia californica resembles nervous system formation in vertebrates. J. Neurosci. 4: 1225-1239.

Jahan-Parwar, B., and S. M. Fredman (1978a) Pedal locomotion in Aplysia. I. Sensory and motor function of foot nerves. Comp. Biochem. Physiol. [A] 60: 459-465.

Jahan-Parwar, B., and S. M. Fredman (1978b) Pedal locomotion in Aplysia. II. Proprioceptive and tactile reflexes. J. Neurophysiol. 41 : 600-608.

Kammer, A. E., and S. C. Kinnamon (1979) Maturation of the flight motor pattern without movement in Manduca sexta. J. Comp. Physiol. 130: 29-37.

Kandel, E. R. (1976) Cellular Basis of Behavior, Freeman, San Francisco.

Kandel, E. R., T. Abrams, L. Bernier, T. J. Carew, R. D. Hawkins, and J. H. Schwartz (1983) Classical conditioning and sensitization share aspects of the same molecular cascade in Aplysia. Cold Spring Harbor Symp. Quant. Biol. 48: 821-830. 
Kanz, J. E., and W. D. Quast (1985) Description of a newly discovered spontaneous behavior, "respiratory pumping seizure," in Aplysia. Soc. Neurosci. Abstr. 78: 3

Kanz, J. E., L. B. Eberly, J. S. Cobbs, and H. M. Pinsker (1979) Neuronal correlates of siphon withdrawal in freely behaving Aplysia. J. Neurophysiol. 42: 1538-1556.

Klein, M., and E. R. Kandel (1978) Presynaptic modulation of voltagedependent $\mathrm{Ca}^{++}$current: Mechanism for behavioral sensitization. Proc. Natl. Acad. Sci. USA 75: 3512-3516.

Klein, M., and E. R. Kandel (1980) Mechanism of calcium current modulation underlying presynaptic facilitation and behavioral sensitization in Aplysia. Proc. Natl. Acad. Sci. USA 77: 6912-6916.

Koester, J. (1983) Respiratory pumping in Aplysia is mediated by two coupled clusters of interneurons. Soc. Neurosci. Abstr. 9: 542.

Konishi, M., and F. Nottebohm (1969) Experimental studies in the ontogeny of avian vocalizations. In Bird Vocalizations, R. A. Hind, ed., Cambridge U. P., Cambridge, UK.

Kriegstein, A. R. (1977a) Development of the nervous system of Aplysia californica. Proc. Natl. Acad. Sci. USA 74: 375-378.

Kriegstein, A. R. (1977b) Stages in the post-hatching development of Aplysia californica. J. Exp. Zool. 199: 275-288.

Kriegstein, A. R., V. Castellucci, and E. R. Kandel (1974) Metamorphosis of Aplysia californica in laboratory culture. Proc. Natl. Acad. Sci. USA 71: 3654-3658.

Kupfermann, I. (1967) Stimulation of egg laying: Possible neuroendocrine function of bag cells of abdominal ganglion of Aplysia californica. Nature 216: 814-815.

Kupfermann, I. (1974a) Feeding behavior in Aplysia: A simple system for the study of motivation. Behav. Biol. 10:1-26.

Kupfermann, I. (1974b) Dissociation of the appetitive and consummatory phases of feeding behavior in Aplysia: A lesion study. Behav. Biol. 10: 89-97.

Kupfermann, I., and E. R. Kandel (1969) Neuronal controls of a behavioral response mediated by the abdominal ganglion of Aplysia. Science 164: 847-850.

Kupfermann, I., and E. R. Kandel (1970) Electrophysiological properties and functional interconnections of the symmetrical neurosecretory clusters (bag cells) in abdominal ganglion of Aplysia. J. Neurophysiol. 33: 865-876.

Kupfermann, I., T. J. Carew, and E. R. Kandel (1974) Local, reflexive and central commands controlling gill and siphon movements in Aplysia californica. J. Neurophysiol. 37: 966-1010.

Lang, F., C. K. Govind, W. J. Costello, and S. I. Green (1977) Developmental neuroethology: Changes in escape locomotion and defensive behavior during growth of the lobster. Science 197: 682-684.

Levine, R. B., and J. W. Truman (1983) Peptide activation of a simple neuronal circuit. Brain Res. 279: 335-338.

Marler, P., and P. Mundinger (1971) Vocal learning in birds. In Ontogeny of Vertebrate Behavior, M. Moltz, ed., Academic, New York.

Maycri, E., P. Browncll, W. D. Branton, and S. B. Simon (1979a) Multiple, prolonged actions of neuroendocrine bag cells on neurons in Aplysia: I. Effects of bursting pacemaker neurons. J. Neurophysiol. 42: $1165-1184$.
Mayeri, E., P. Brownell, W. D. Branton, and S. B. Simon (1979b) Multiple, prolonged actions of neuroendocrine bag cells on neurons in Aplysia: II. Effects on beating pacemakers and silent neurons. J. Neurophysiol. 42: 1185-1 197.

McAllister, L. B., R. H. Scheller, E. R. Kandel, and R. Axel (1983) In situ hybridization to study the origin and fate of identified neurons. Science 222: 800-808.

Nolen, T. G., E. Marcus, and T. J. Carew (1987) Development of learning and memory in Aplysia. III. Central neuronal correlates. J. Neurosci. 7: 144-153.

Ocorr, K. A., E. T. Walters, and J. H. Byrne (1985) Associative conditioning analog selectively increases cAMP levels of tail sensory neurons in Aplysia. Proc. Natl. Acad. Sci. USA 82: 2538-2552.

Peretz, B. (1969) Central neuron initiation of periodic gill movements Science 166: 1167-1172.

Peretz, B., J. W. Jacklet, and K. Lukowiak (1976) Habituation of reflexes in Aplysia. Contribution of the peripheral and central nervous systems. Science 191: 396-399.

Perlman, A. J. (1979) Central and peripheral control of siphon-withdrawal reflex in Aplysia californica. J. Neurophysiol. 42: 510-529.

Pinsker, H., I. Kupfermann, V. Castellucci, and E. Kandel (1970) Habituation and dishabituation of the gill-withdrawal reflex in Aplysia. Science 167: 1740-1742.

Rankin, C. H., and T. J. Carew (1987) Development of learning and memory in Aplysia. II. Habituation and dishabituation. J. Neurosci. 7: 133-143.

Schacher, S., E. R. Kandel, and R. Woolley (1979a) Development of neurons in the abdominal ganglion of Aplysia californica. I. Axosomatic synaptic contacts. Dev. Biol. 71: 163-175.

Schacher, S., E. R. Kandel, and R. Woolley (1979b) Development of neurons in the abdominal ganglion of Aplysia californica. II. Nonneural support cells. Dev. Biol. 71: 176-190.

Siegel, S. (1956) Nonparametric Statistics for the Behavioral Sciences, McGraw-Hill, New York.

Stopfer, M., and T. J. Carew (1986) A quantitative analysis of the relationship between gill amplitude and siphon duration in the defensive withdrawal reflex of Aplysia. Behav. Neurosci. (in press).

Truman, J. W. (1980) Eclosion hormone: Its role in coordinating ecdysial events in insects. In Insect Biology in the Future, M. Locke and D. S. Smith, eds., Academic, New York.

Walters, E. T., and J. H. Byrne (1983) Associative conditioning of a single sensory neuron suggests a cellular mechanism for learning. Science 219: 405-408.

Walters, E. T., J. H. Byrne, T. J. Carew, and E. R. Kandel (1983) Mechanoafferent neurons innervating the tail of Aplysia. I. Response properties and synaptic connections. J. Neurophysiol. 50: 1522-1542.

Weisel, T. N., and D. H. Hubel (1965) Comparison of the effects of unilateral and bilateral eye closure on cortical unit response in kittens. J. Physiol. (Lond.) 28: 1029-1041.

Winer, B. (1962) Statistical Principles in Experimental Design, McGraw-Hill, New York. 